\title{
Measurements of internal cracking in punching test slabs without shear reinforcement
}

\author{
Jürgen Einpaul \\ Former research assistant, IBETON-ENAC, École Polytechnique Fédérale \\ de Lausanne, Lausanne, Switzerland (corresponding author: \\ jyrgen.einpaul@gmail.com) \\ Miguel Fernández Ruiz \\ Senior lecturer and scientist, IBETON-ENAC, École Polytechnique Fédérale \\ de Lausanne, Lausanne, Switzerland
}

\author{
Aurelio Muttoni \\ Professor, IBETON-ENAC, École Polytechnique Fédérale de Lausanne, \\ Lausanne, Switzerland
}

Advancing the knowledge about the punching behaviour of flat slabs has been held back by the fact that only indirect measurements of the internal failure mechanism have typically been available. In this paper, a novel experimental approach for tracking the formation and development of cracks inside punching test specimens is presented. In six full-scale specimens without shear reinforcement, 48-64 measurement points were installed inside small holes drilled on the soffits of the slabs. During the punching tests, the displacements of these points were followed at various levels of load with a high-precision coordinate measuring arm. Development of inclined flexural cracks (called the critical shear cracks) from the tension chord to the neutral axis was observed in every specimen. In some cases, the punching failures occurred along these cracks. However, in other cases, new lower-angled failure cracks developed, either at the moment of failure or already at earlier stages of loading. These cracks had very different patterns of development, even between two monitored sides of the same specimen, although the specimens were nominally axis-symmetric.

\section{Notation}

a shear span (distance between the loading point and the edge of the support)

$a_{\text {eff }} \quad$ effective shear span (calculated as $m / v$ )

$b \quad$ element width

$b_{\text {per }} \quad$ length of a punching control perimeter

$d \quad$ effective depth of a slab

$d_{\text {c }} \quad$ column diameter

$d_{\text {strong }}$ effective depth of a slab on the strong axis

$d_{\text {weak }}$ effective depth of a slab on the weak axis

$f_{\mathrm{c}} \quad$ average compressive concrete strength (cylinder)

$f_{\mathrm{y}} \quad$ average yield strength of reinforcing steel

$l \quad$ length of an element

$M \quad$ bending moment

$m \quad$ bending moment, per unit width

$r \quad$ distance from the centre of the column

$r_{\mathrm{c}} \quad$ column radius

$r_{0} \quad$ radius of the critical shear crack at the level of tensile reinforcement

$V \quad$ shear force

$V_{\mathrm{R}} \quad$ measured punching shear capacity (maximum applied load during the test)

$v \quad$ shear force, per unit width

$w_{\text {cr }} \quad$ crack width

$\Delta l_{i-j} \quad$ relative displacement between points $i$ and $j$

$\Delta w \quad$ vertical deviation of the slab soffit from a conical shape

$\Delta w_{\max }$ maximum vertical deviation of the slab soffit from a conical shape

$\begin{array}{ll}\delta_{\text {crack }} & \begin{array}{l}\text { sliding displacement of the critical shear crack at } \\ \text { punching failure }\end{array} \\ \varepsilon_{\mathrm{c}, \mathrm{r}} & \begin{array}{l}\text { radial strain on the slab soffit } \\ \text { tangential strain on the slab soffit } \\ \varepsilon_{\mathrm{c}, \mathrm{t}}\end{array} \\ \varepsilon_{i-j} & \begin{array}{l}\text { average strain between points } i \text { and } j \\ \text { principal strains }\end{array} \\ \varepsilon_{\mathrm{I}}, \varepsilon_{\mathrm{II}} & \begin{array}{l}\text { reinforcement ratio } \\ \rho\end{array} \\ \rho_{\text {strong }} & \begin{array}{l}\text { reinforcement ratio on the strong axis (with larger } \\ \text { effective depth) }\end{array} \\ \rho_{\text {weak }} & \begin{array}{l}\text { reinforcement ratio on the weak axis (with lower } \\ \text { effective depth) }\end{array} \\ \chi_{\mathrm{t}} & \begin{array}{l}\text { tangential curvature } \\ \psi\end{array} \\ \psi_{\text {crack }} & \begin{array}{l}\text { slab rotation } \\ \text { rotan of the critical shear crack }\end{array}\end{array}$

\section{Introduction}

Punching shear failures, which may occur around columns or concentrated loads in reinforced concrete flat slabs, can in many cases govern the capacity and thus also the design of such slabs. Several analytical or empirical models to predict the punching strength and deformation capacity of slabs both with and without transverse reinforcement have been proposed during decades of research (fib, 2001). It is often assumed that the punching shear behaviour of two-way slabs is analogous to one-way shear in beams. In the latter case, the formation and propagation of cracking can be directly measured by mechanical (Campana et al., 2013; Vollum and Fang, 2014) or 
optical means (Cavagnis et al., 2015). However, the development of punching shear cracks occurs inside the slabs and is thus difficult to observe in a direct manner. The aim of this paper is to improve the knowledge of internal crack development in slabs during loading by means of a novel measurement technique. The results obtained are described in detail for six isolated punching test specimens.

Previous experiments have shown that the post-failure cracking patterns on beam specimens without shear reinforcement can be notably different from those observed on the saw-cut surfaces of punching test slabs. In Figure 1, some previously tested specimens are compared. In sufficiently slender beams (such as SC12b (Campana et al., 2013), shown in Figure 1(a)), the tension chord is normally cracked over almost the whole length of the element. These flexural cracks develop towards the neutral axis and may propagate into the compression chord. Among these cracks, the shear strength is normally controlled by one, called the critical shear crack (Cavagnis et al., 2015), which may progress to become the failure crack (as in specimen SC12b shown in Figure 1(a)), or which triggers the development of a new crack leading to failure in a sudden manner (Cavagnis et al., 2015).

With respect to punching failures, Figure 1(b) shows a two-way slab specimen (PF22 of Clément et al. (2012)) with similar geometry (slab depth $400 \mathrm{~mm}$, distance between the load and the support $1380 \mathrm{~mm})$ and reinforcement ratio $(\rho=1.5 \%)$ as the previous beam SC12b. Internal measurements similar to the ones described in this paper were performed during this test. Flexural cracking detected with the internal measurement system and visible on the saw-cut is concentrated in the zone directly above the column. The furthermost flexural crack from the column edge (the critical shear crack) is inclined at approximately $45^{\circ}$. This crack propagates to the vicinity of the compression chord, influencing its stress state. The failure crack, which does not touch the critical shear crack in this specimen, can be seen as having a much flatter angle than in beam elements. Even at the last measurement step (at $95 \%$ of the failure load) before a sudden punching failure, the internal measurement system did not detect the failure crack, which indicates its sudden appearance and propagation. However, the behaviour of other previously tested specimens might have been different. For instance, on the saw-cut of specimen PG3 of Guandalini et al. (2009) with $\rho=0 \cdot 33 \%$, which is shown in Figure 1(c), failure cracks with steeper angles can be observed. In some cases, these cracks turn quasi-vertical close to the tension chord, which suggests a flexural origin of this part of the crack and can thus be assumed to be coincident with the critical shear crack. Even in slabs with non-symmetric flexural reinforcement (PT23 of Sagaseta et al. (2011) with $\rho_{\text {min }}=0.35 \%$ and $\rho_{\max }=0.80 \%$ in Figure $\left.1(\mathrm{~d})\right)$, the two types of failure cracks have been observed to occur in the same specimen. In the direction with the lower amount of flexural reinforcement, a steeper failure crack can be seen, whereas the failure crack in the direction with the higher reinforcement ratio has a lower angle, similar to that of PF22 (Figure 1(b)).

The differences between the flexural behaviour of one-way and two-way specimens can be explained by the capacity of two-way slabs to carry bending moments in radial and tangential directions (Figure 2(a)), whereas only one direction of moment transfer is possible in one-way beams (Figure 2(b)). Therefore, for elements with similar distances between the loading point and the support, the radial bending moment in a two-way slab is lower than in a one-way beam. Thus, the ratio of shear slenderness ald (or equivalently $M / V d$ ), which is

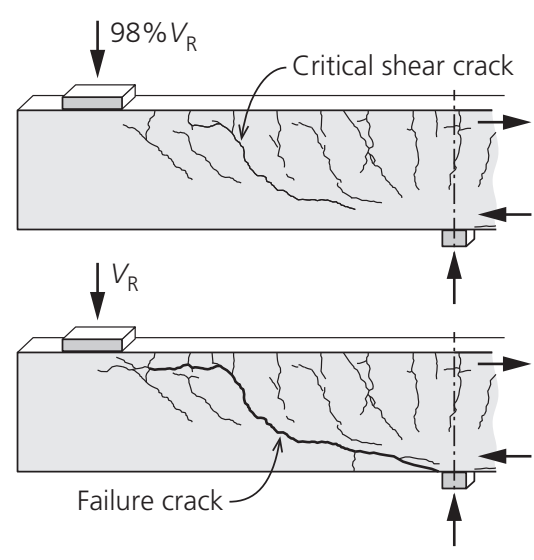

(a)

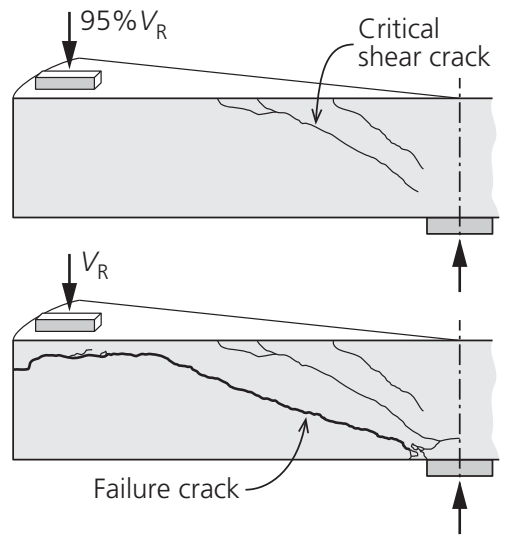

(b)
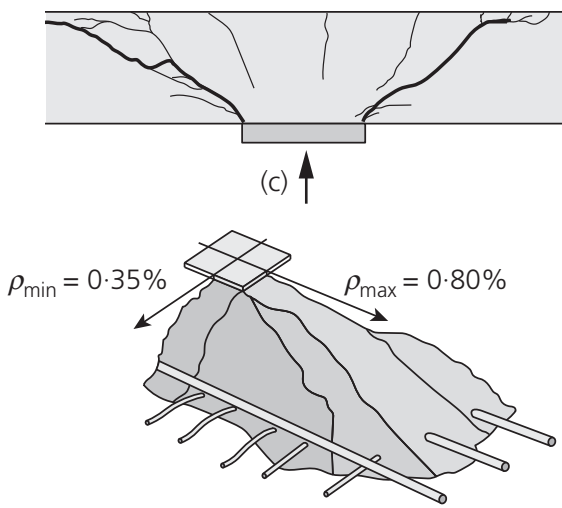

(d)

Figure 1. Comparison between the cracking patterns in (a) one-way (beam) specimen SC12b of Campana et al. $(2013)(\rho=1 \cdot 5 \%)$; (b) saw-cut surface of two-way (slab) specimen PF22 of Clément et al. (2012) ( $\rho=1.5 \%)$; (c) saw-cut surface of specimen PG3 of Guandalini et al. (2009) with low flexural reinforcement ratio ( $\rho=0.33 \%)$; (d) punching cone of specimen PT23 of Sagaseta et al. (2011) with unequal reinforcement ratios in two directions (only a quarter of the slab is shown) 
known to influence the shear strength of elements without shear reinforcement (Kani, 1964), is significantly smaller in a two-way slab than in a corresponding beam (the effective shear span $a_{\text {eff }}$ in two-way slabs can be graphically shown as a gradient of the radial moment diagram (Figure 2(a)). Owing to the rapid decrease of the radial bending moment with increasing distance from the column, circular flexural cracking only occurs close to the column. In addition, because the width of the sector elements in axisymmetric slabs increases linearly with distance from the column, the unitary shear force, in the case when load in the column region is neglected, decreases hyperbolically (Figure 2(a)). In the uncracked region,
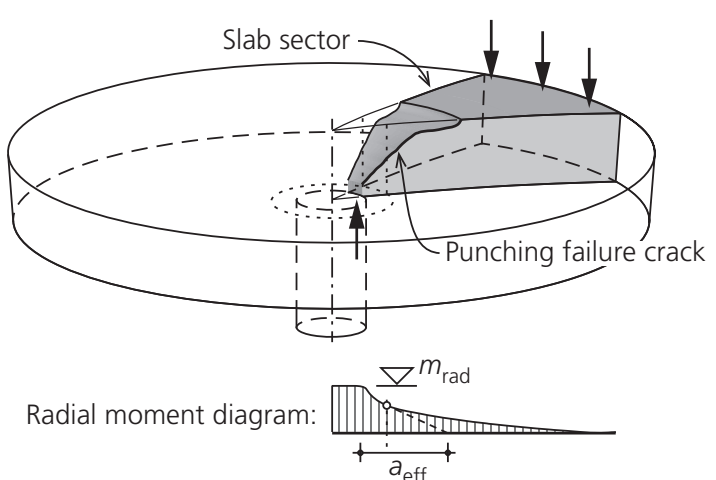

Tangential moment diagram:

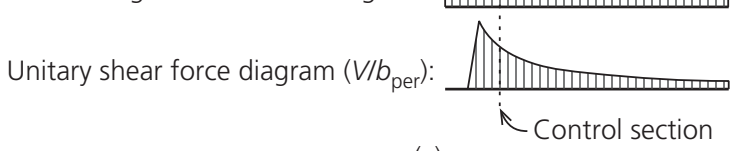

(a)

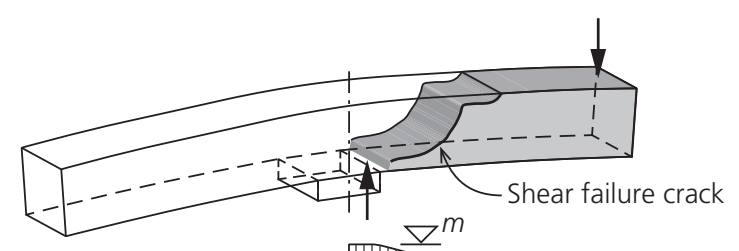

Bending moment diagram:

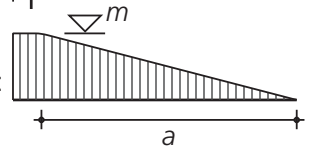

Unitary shear force diagram $(V / b)$ :

(b)

Figure 2. Distribution of moments and shear stresses:

(a) two-way (slab) specimens; (b) one-way (beam) specimens the shear capacity of a slab is thus normally sufficient and punching strength is controlled by the failure of a direct strut close to the edge of the column (Muttoni and Fernández Ruiz, 2010b).

\section{Experimental programme}

This paper presents a detailed analysis of the external and internal measurements performed during symmetric punching tests of six $250 \mathrm{~mm}$ thick octagonal reinforced concrete slabs. All the slabs were without shear reinforcement. The slabs were loaded through eight openings close to the edge of the slab by pulling these points downwards by means of four hydraulic jacks. Specimens were supported on a round steel plate in the centre that simulated the column. The varied parameters were the diameter of the support plate $d_{\mathrm{c}}(166$, 330 and $660 \mathrm{~mm}$ ) and the flexural reinforcement ratio $\rho$ (nominal values $0.75 \%$ and $1.50 \%$ ). The geometry of the slabs was kept constant and material parameters were similar in all of the tests (refer to Table 1). It was observed that (for both reinforcement ratios) the average shear stress at failure on a control perimeter located at $d / 2$ from the column edge decreased with increasing support size. The main results of the campaign (without the details on the internal measurements) are described and further analysed by Einpaul et al. (2016).

\section{External measurements}

The slabs were instrumented with various measurement devices (Figure 3(a)): (a) the applied load was measured using four load cells on the load distribution elements and four load cells between the strong floor and the hydraulic jacks; $(b)$ the slab rotation was tracked with four inclinometers on the main axes on the top surface close to the edges of the slab; $(c)$ vertical displacement profiles on the top and bottom slab surfaces were measured with linear variable differential transformers (LVDTs) on the east-west (E-W) axis (west from the column) (Figure 3(b)); (d) column settlement and rotation were measured with three vertical LVDTs; (e) tangential concrete surface strains were measured with three strain gauges (base length $50 \mathrm{~mm}$ ) glued on the concrete surface on the bottom face of the slab south from the column and perpendicular to the north-south $(\mathrm{N}-\mathrm{S})$ axis; and $(f)$ radial concrete surface strains were measured with three strain gauges oriented along the $\mathrm{E}-\mathrm{W}$ axis west from the column.

Table 1. Main parameters and main results of the test specimens (remark: $V_{R}$ refers to the maximum applied load during the test)

\begin{tabular}{|c|c|c|c|c|c|c|c|c|c|c|c|}
\hline Slab & $d_{c}: \mathrm{mm}$ & $d_{\mathrm{avg}}: \mathrm{mm}$ & $d_{\text {strong: }}: m m$ & $d_{\text {weak }}: \mathrm{mm}$ & $\rho_{\text {avg }}: \%$ & $\rho_{\text {strong: }} \%$ & $\rho_{\text {weak }}: \%$ & $f_{\mathrm{y}}: \mathrm{MPa}$ & $f_{\mathrm{c}}: \mathrm{MPa}$ & $\psi_{\mathrm{R}, \text { test }}:$ mrad & $V_{R}: k N$ \\
\hline PE5 & 660 & 210 & 220 & 200 & $1 \cdot 50$ & $1 \cdot 43$ & 1.57 & 542 & $36 \cdot 7$ & $12 \cdot 7$ & 1476 \\
\hline PE8 & 330 & 214 & 224 & 204 & $1 \cdot 47$ & $1 \cdot 40$ & 1.54 & 542 & $42 \cdot 0$ & $8 \cdot 7$ & 1091 \\
\hline PE7 & 166 & 213 & 223 & 203 & $1 \cdot 47$ & $1 \cdot 41$ & 1.55 & 542 & $42 \cdot 5$ & $6 \cdot 7$ & 871 \\
\hline PE12 & 660 & 212 & 220 & 204 & $0 \cdot 76$ & 0.73 & 0.79 & 538 & $37 \cdot 6$ & $29 \cdot 4$ & 1206 \\
\hline PE9 & 330 & 218 & 226 & 210 & $0 \cdot 74$ & $0 \cdot 71$ & $0 \cdot 77$ & 538 & $44 \cdot 1$ & $13 \cdot 8$ & 935 \\
\hline PE11 & 166 & 215 & 223 & 207 & 0.75 & 0.72 & 0.78 & 538 & 37.5 & $10 \cdot 1$ & 712 \\
\hline
\end{tabular}




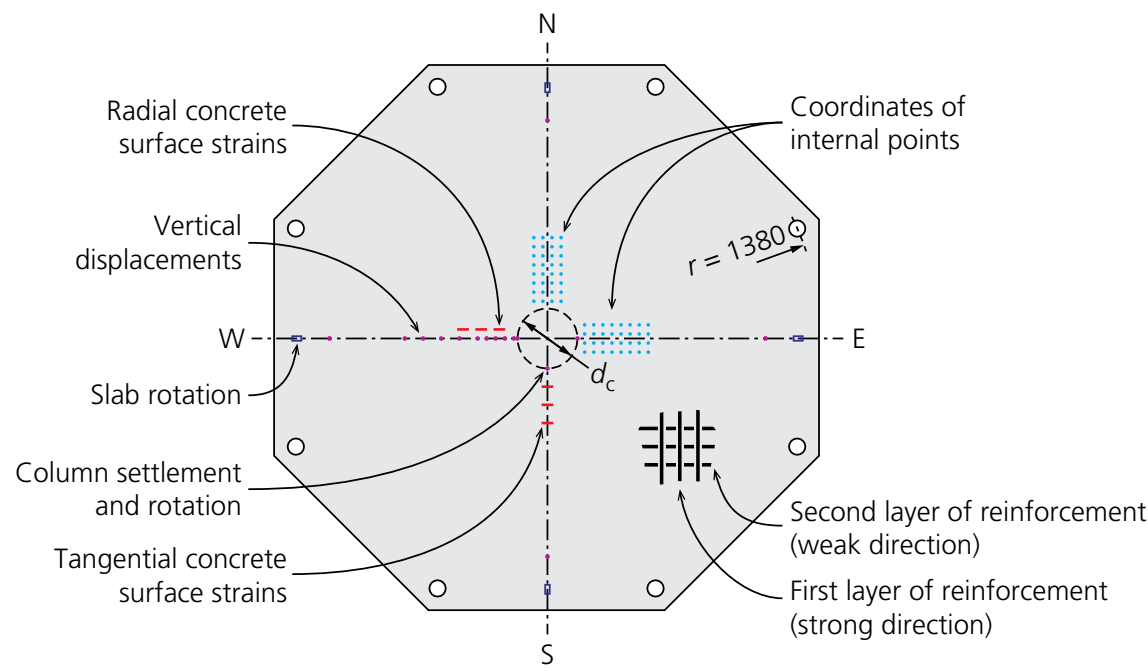

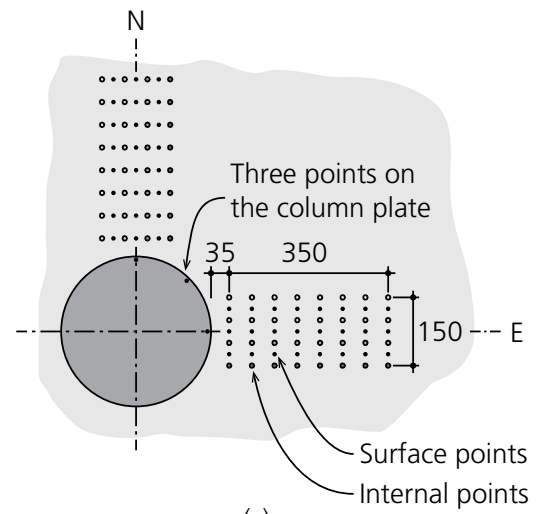

(c)

(a)

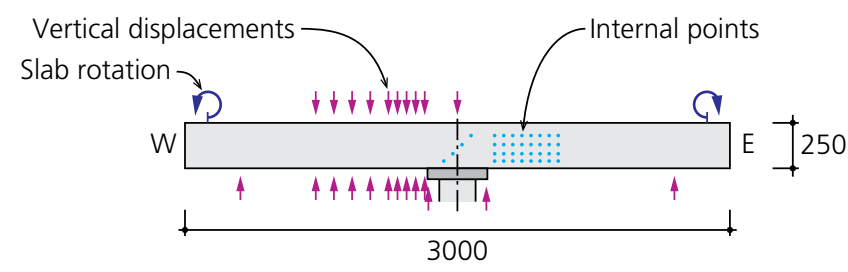

(b)

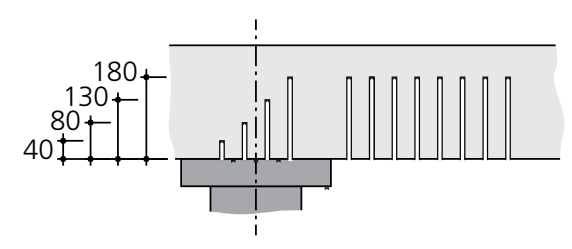

(d)

Figure 3. Geometry and instrumentation of the specimens: (a) plan view of the soffit of the specimen; (b) section view of the specimen (only LVDTs, inclinometers and internal points shown); (c) coordinate measurement points close to the column on the slab soffit; (d) section cut of the specimen through the internal coordinate measurement points (dimensions in $\mathrm{mm}$ )

All the measurement readings were set to zero before starting the test, assuming that the slab deformations under self-weight of the slab and the testing equipment were negligible (approximately $65 \mathrm{kN}$, added later to the measured load).

\section{Internal measurements}

The internal measurements were performed with a commercial coordinate measuring arm (FaroArm Quantum) that could determine the location of its probe in the space by measuring the rotations of its seven axes. In order to follow the internal cracking of the slab, a number of holes were drilled with a $10 \mathrm{~mm}$ drill bit in the bottom surface (soffit) of the specimens. After the holes had been cleaned of concrete dust, small steel cylinders with conical sockets as measurement points were glued in the ends of each hole. To access the measurement points with the probe, the arm was extended with a stainless steel bar (length $200 \mathrm{~mm}$, dia. $7 \mathrm{~mm}$ ). The flexural deformations of the extension bar were indirectly measured with strain gauges glued close to the fixed end of the bar. Using these strain measurements, the precision of the system was improved by correcting the obtained coordinates of the internal points with the deflections of the extension bar. The manufacturer-declared precision (radius of the point cloud) of the measuring arm was $0.020 \mathrm{~mm}$. Calibration of the strain gauges on the extension bar, performed before each test, resulted in a standard deviation of the additional error below $0.010 \mathrm{~mm}$.

The internal measurement points were located along the two main axes of the specimens in the north (strong axis) and east (weak axis) directions from the column in three or four lines (depending on the size of the column) with eight points in each line (Figure 3(c)). The distance between the points in each line, as well as between the lines, was approximately $50 \mathrm{~mm}$. The depth of the internal points from the slab soffit varied between 40 and $180 \mathrm{~mm}$ (Figure 3(d)) so that the points formed a regular mesh in a vertical plane. Reference points were glued between the holes on the slab surface as well as on the column plate. The actual layout of the points varied slightly due to the precision of drilling and the need to avoid reinforcing bars.

The specimen was loaded by pumping oil into the hydraulic jacks. The load was applied in steps, with larger load increments at the beginning of the test and smaller increments closer to the failure. After applying each load increment, the pumping was stopped, which caused the load to decrease slightly. After approximately $10 \mathrm{~min}$, when the rate of decrease of load had diminished, the coordinates of each point were measured sequentially (Figure 4). One measurement step lasted for 10 to $15 \mathrm{~min}$. 


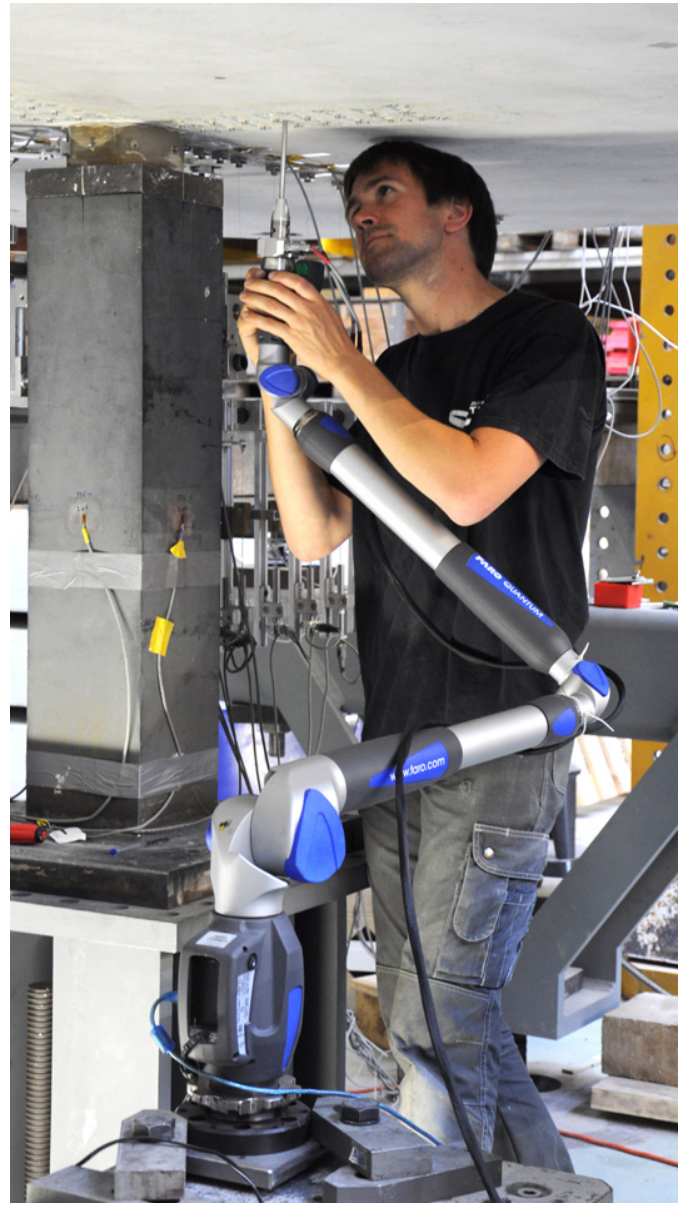

Figure 4. Performing internal measurements with FaroArm

In addition to the accuracy of the measurement arm and the strain gauges on the extension bar, the potential sources of erroneous measurements included accidental contacts of the extension bar with the walls of the drilled holes, dust or concrete debris on the measurement points, loose points due to failure of the glue or cracks in concrete where the points were glued. As the points were located in narrow holes, these aspects were difficult to check visually. Also, slab movements or crack propagation during a measurement sequence may have influenced the calculated relative displacements between the points. However, comparing the independent coordinate measurements between different load steps and at adjacent measurement points allowed filtering out clearly erroneous measurements that were removed from the subsequent analysis (refer to an example of raw measurement results in the Appendix of the paper). Whereas the density of the mesh of measurement points $(50 \mathrm{~mm})$ and the precision of the system $(+/-0.03 \mathrm{~mm})$ were insufficient to obtain reliable information about the compressive strains in concrete (which have an order of magnitude of $1 \% 0$ ), the precision was clearly sufficient to follow the formation and kinematics of cracks (in an order of magnitude of $0.1 \mathrm{~mm}$ ).

\section{Experimental results}

All the specimens failed in punching with a sudden drop of the load (the maximum measured loads are shown in Table 1). It is interesting to note that the failure of some specimens occurred while the loading was stopped in order to perform measurements and the load had decreased below the maximum that had been applied before. In this paper, selected measurements performed in this test campaign are described in detail. A more general analysis and a comparison of the test results to some codes of practice can be consulted elsewhere (Einpaul et al., 2016).

After the test, in order to observe the internal cracking patterns, all specimens were cut along the E-W axis, whereas the northern halves were additionally cut along the $\mathrm{N}-\mathrm{S}$ axis. One wide crack, referred to as a 'failure crack', was clearly distinguishable on all the saw-cut surfaces (Figure 5). This crack extended from the edge of the column plate in the slab soffit to the tensile reinforcement layer (except on the east side of PE12, where the crack started at some distance from the column). The shapes and angles of this crack varied significantly between specimens and even between different sides of one specimen. On most saw-cut faces, some narrower flexural cracks were also visible that extended from the top surface of the slab either to the bottom half of the slab or to the failure crack. As intended, the presence of holes for the internal measurements did not have a significant influence on the cracking patterns and punching performance.

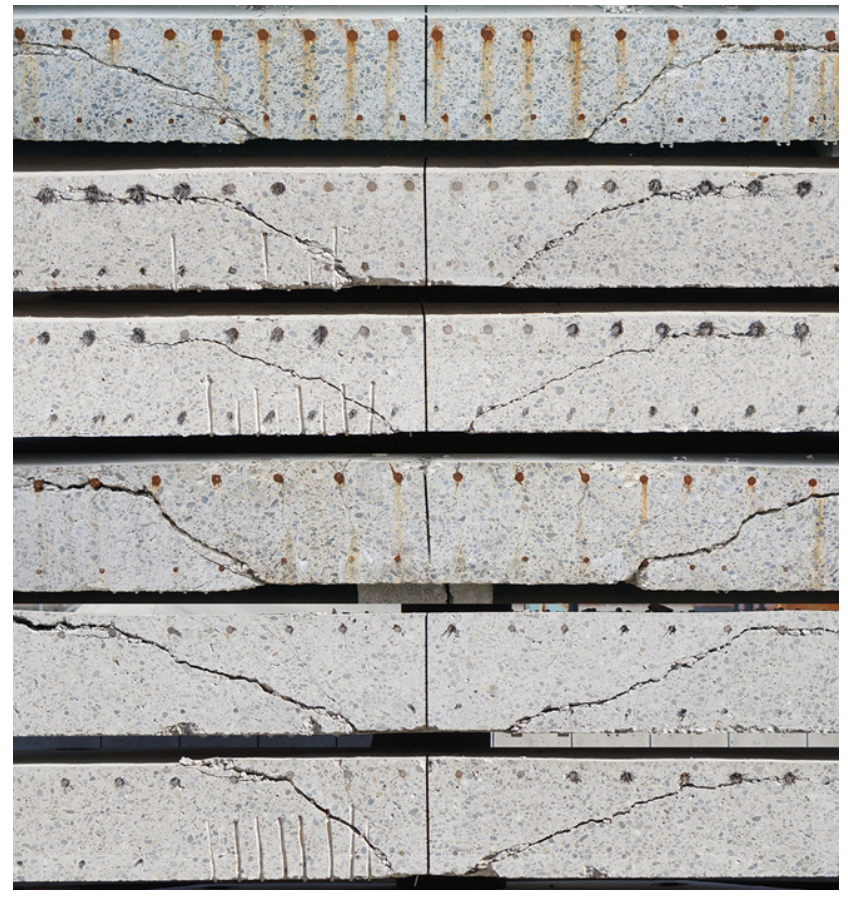

Figure 5. Photographs of saw-cuts of the specimens along the E-W axis (from top to bottom: PE5, PE8, PE7, PE12, PE9, PE11, i.e. decreasing column size and reinforcement ratio) 


\section{Flexural response of specimens}

Regarding the flexural response of a specimen, three phases can be observed, characterised by different stiffnesses of the load-rotation curve (Figure 6(a)).

- Elastic, uncracked phase before the first flexural cracks appear over the column. In this phase, slab deformations can be suitably predicted by means of linear-elastic slab theory.

- Cracked phase, where circular flexural cracks develop around the column. The cracks incline towards the centre due to the influence of shear stresses in the slab. The furthermost circular, flexural crack, which is referred to as the critical shear crack, extends up to the vicinity of the column edge. In addition, radial cracking starts spreading towards the edge of the slab. Starting from this phase, the flexural behaviour is suitably approximated by the conical model of Kinnunen and Nylander (1960), which is shown in Figure 6(b). According to this model, the deformed shape of a specimen is assumed to be spherical in the slab region close to the column (within a radius $r_{0}$, which is defined by the location of the critical shear crack) and conical with a sloping angle $\psi$ in the slab part further from the column. The radius $r_{0}$ has been suggested to be selected as $r_{0}=r_{\mathrm{c}}+d$, which corresponds to an inclination of the critical shear crack of $45^{\circ}$ (Muttoni, 2008). According to Kinnunen and Nylander (1960), internal forces can be calculated assuming a bilinear elastic-plastic moment-curvature relationship. For low reinforcement ratios, concrete tensile strength and tension stiffening should also be accounted

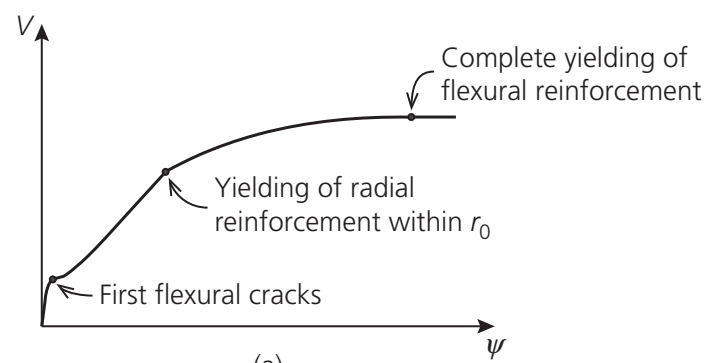

(a)

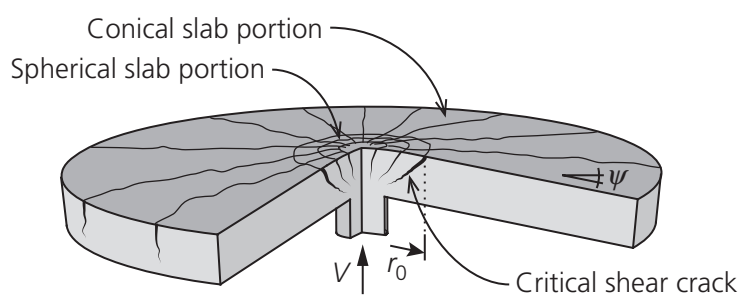

(b)

Figure 6. (a) Load-rotation curve. (b) Assumed deformed shape of a specimen for by using a quadrilinear moment-curvature law (Muttoni, 2008).

- After yielding of radial reinforcement within the radius $r_{0}$, only the increase of tangential moments in the conical part can carry the additional load. The stiffness of the load-rotation response therefore decreases. Flexural strength of the specimen is reached when tangential reinforcement in the whole specimen reaches yielding.

\section{Deformations of the slab soffit}

The conical flexural model of Kinnunen and Nylander (1960) can successfully predict the global behaviour (load-rotation response) of the specimens. However, detailed observations indicate that the actual slab behaviour may exhibit some small differences. Figure 7(a) shows the deviations of the slab soffit deflection from the theoretical conical shape, measured with a series of LVDTs on the west side of the column in specimen PE8. In the elastic uncracked phase, the slab is curved both in the tangential as well as in the radial direction, as predicted by the linear-elastic slab theory. Due to the radial curvature, compressive radial strains appear on the slab soffit (refer to the insert in Figure 7(a)). After cracking of concrete due to the radial moments, the radial curvature starts to concentrate in the column region (the spherical slab portion in Figure 6(b)), which decreases the rate of increase of radial compressive strains (measured on the soffit at some distance from the column edge). When the circular cracks are fully developed, the radial strains on the soffit are nearly constant. In this phase, the additional flexural deformations of the slab are related to the conical model.

In addition, at already early stages of loading, slight penetration of the column plate into the slab is observed close to the column edge (this can be also in part explained by crushing of the thin layer of plaster placed between the column plate and the slab). However, this column penetration is only a local phenomenon as it does not have any effect on the radial soffit strains further from the column edge.

At load levels closer to the punching strength, the development of strains on the slab soffit may enter a new phase where the radial compression on the soffit begins to decrease. At failure, even tensile strains have been measured in some of the previous experiments (Guandalini et al., 2009; Kinnunen and Nylander, 1960). This phase sometimes starts immediately before the failure (or even when the load is, in fact, decreasing, as in specimen PE8 (Figure 7(a)) or already at $80 \%$ of punching strength, as witnessed, for example, in specimen PE5 (Figure 7(b)). The decrease of compressive strains is also measured by radial strain gauges further from the column edge (200 or $300 \mathrm{~mm}$ ), although the reduction is less substantial there. It can also be noted that the maximum soffit deviation $\Delta w_{\max }$ from the theoretical conical shape starts to increase faster in this phase than in the earlier stages of loading. 


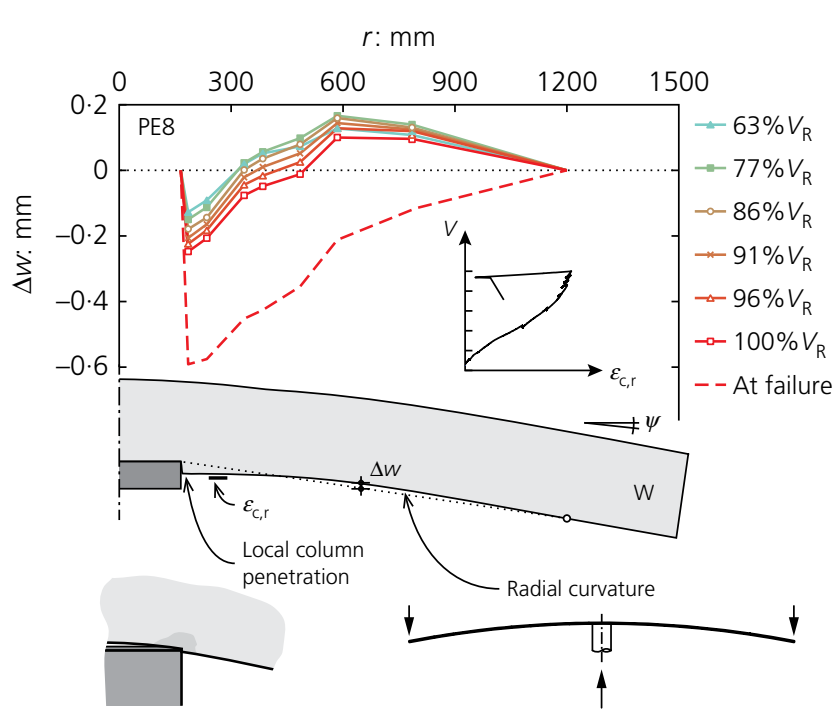

(a)

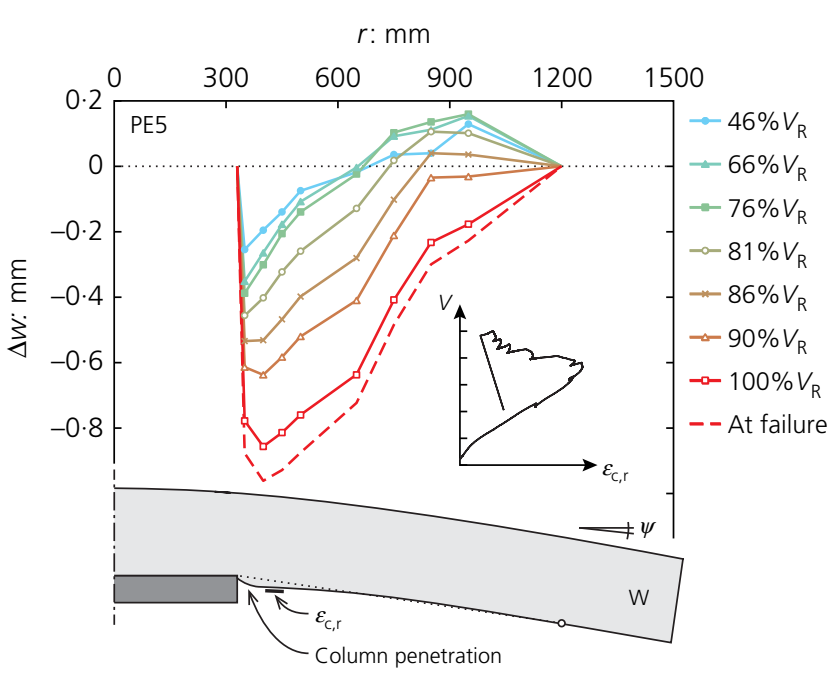

(b)

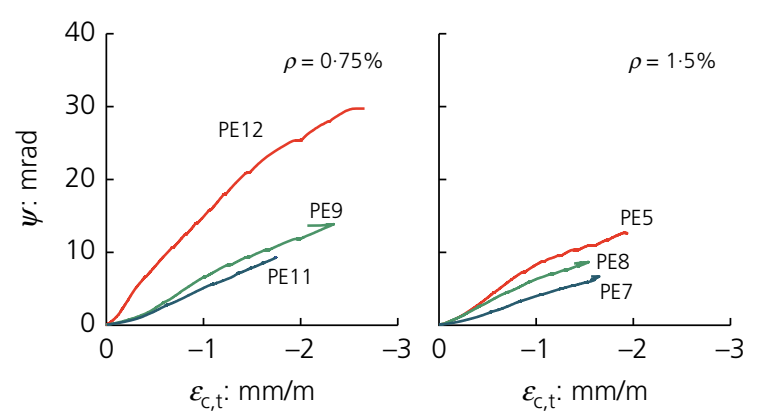

(c)

Figure 7. Deformations of the slab soffit in comparison to the conical shape: (a) deviations of the slab soffit compared to the conical shape, specimen PE8; (b) deviations of the slab soffit compared to the conical shape, specimen PE5; (c) tangential strains at $100 \mathrm{~mm}$ from the column on the strong axis ( $\mathrm{S}$ from the column) as a function of average slab rotation
Figure 7(c) shows the tangential compressive strains on the slab soffit at $100 \mathrm{~mm}$ from the edge of the column as a function of the average slab rotation (measured on the south side of the column, refer to Figure 3(a)). The ultimate strains range from $-1 \cdot 5 \%$ to $-2 \cdot 6 \%$ in different specimens. This remains below the strains corresponding to the compressive strength of normal strength concrete in biaxial compression as reported by Kupfer (1973). According to the conical model, the tangential curvature and thus the tangential strains on the slab soffit are proportional to slab rotation (expressed from a geometrical compatibility condition as $\chi_{\mathrm{t}}=-\psi / r$ ). This was confirmed by measurements, although on the south side of the column, slightly larger strains than predicted were measured close to the failure.

\section{Internal cracking}

Internal cracking of the specimens was monitored with the coordinate measuring system on the eastern and northern sides of the column. Details about the treatment of the data obtained are given in the Appendix of the paper.

The cracks that were detected with the internal measurement system were always also found on the saw-cuts. On the other hand, in some places where no strains were measured in any of the measurement steps before the failure, wide failure cracks were seen on saw-cut surfaces, which indicates that these cracks appeared at failure or very close to it. Such cracks are shown with dashed lines in Figure 8 in the locations where the absence of a crack was confirmed by reliable coordinate measurements. For all the measured cracks, the direction of crack opening did not change significantly between the load steps and was approximately perpendicular to the crack lips, indicating that the crack opening displacements were larger than the crack sliding displacements in the parts of the cracks where the measurement points were located (it should also be noted that the plotted crack widths are projections on a vertical plane and some variability may thus be related to actual variations in crack angles between the measurement points). The exact centres of rotation of the slab sectors could not be detected due to the insufficient precision of the coordinate measurements. However, the fact that the points on the slab soffit moved towards the column and the points deeper inside the slab moved further from the column indicates that the vertical position of the centre of rotation was located within the specimen.

\section{Discussion of the test results}

\section{Development of the critical shear cracks}

The critical shear crack (the furthermost inclined circular crack of flexural origin) was followed in all the cases, except in the east direction of specimen PE8 (Figure 8(b)). These cracks $(1,3,5-11,13-15$ in Figure 8$)$ were first observed as having occurred already at approximately $50 \%$ of the failure load. Widths of the critical shear cracks in different specimens, 


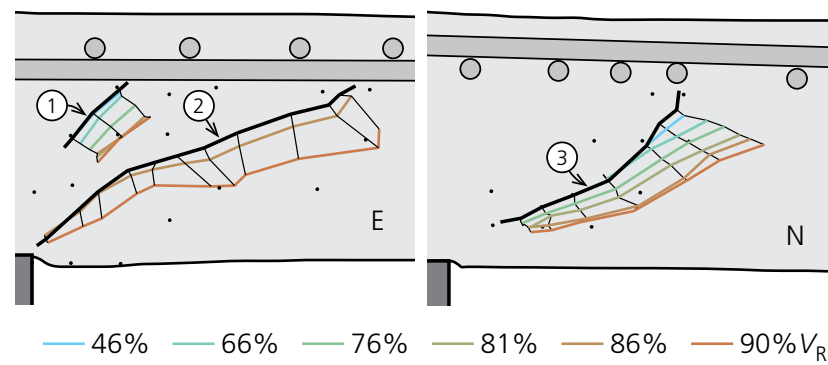

(a)

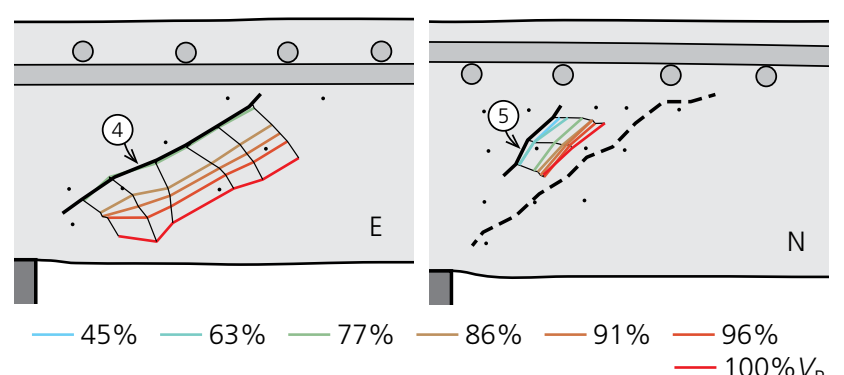

(b)

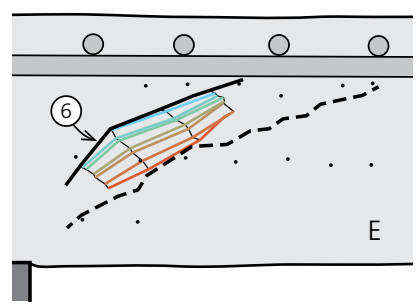

$-45 \%-62 \%-72 \%$

(c)

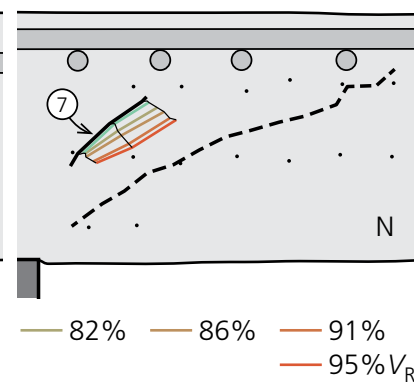

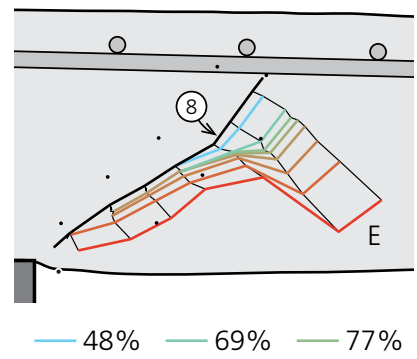

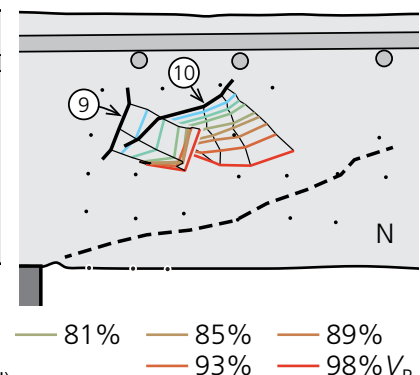

(d)
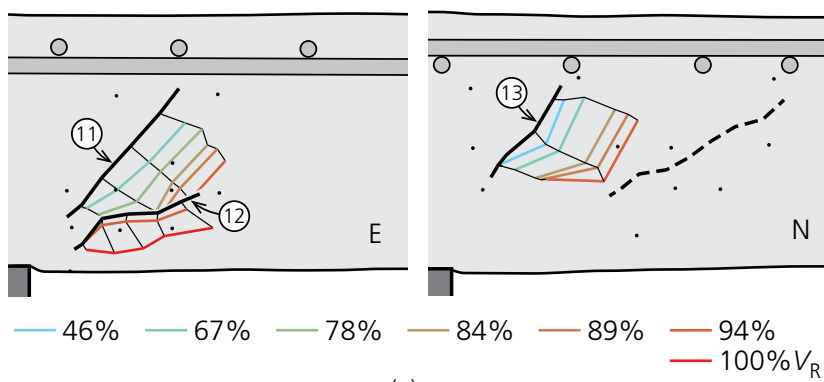

(e)
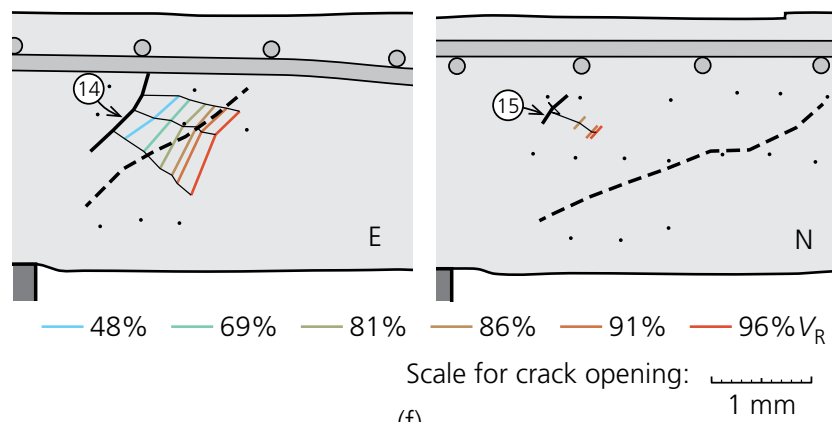

(f)

Figure 8. Crack widths and opening directions (dashed lines indicate the cracks that were first detected after the punching failure): (a) PE5 $\left(d_{\mathrm{c}}=660 \mathrm{~mm} ; \rho=1.5 \%\right)$; (b) PE8 $\left(d_{\mathrm{c}}=330 \mathrm{~mm} ; \rho=1.5 \%\right)$; (c) PE7 $\left(d_{\mathrm{c}}=166 \mathrm{~mm} ; \rho=1.5 \%\right)$; (d) PE12 $\left(d_{\mathrm{c}}=660 \mathrm{~mm} ; \rho=0.75 \%\right)$; (e) PE9 ( $\left.d_{c}=330 \mathrm{~mm} ; \rho=0.75 \%\right)$; (f) PE11 ( $\left.d_{c}=166 \mathrm{~mm} ; \rho=0.75 \%\right)$

measured at the level of the highest internal measurement points (approximately $170 \mathrm{~mm}$ from the bottom face of the slab), are shown as a function of slab rotation in Figure 9. It can be seen that the crack widths at punching failure were larger in slabs with lower reinforcement ratios. This shows that these cracks are mainly related to bending. However, the critical shear crack widths before failure did not depend significantly on the column size. It can also be noted that in the case of larger columns, the cracks outside the perimeter of the column plate started opening at larger rotations. This can be explained by other flexural cracks closer to the centre of the column developing first (outside the monitored range). This is confirmed by the measurements performed in slab PE12, where two flexural cracks were located within the region of the internal measurement points (Figure 8(d)). It can be seen that the crack which was closer to the centre (crack 9) started opening at a lower rotation. However, another crack (crack 10) appeared further from the column and became the critical shear crack later (in one-way elements, similar behaviour has also been observed by Cavagnis et al. (2015)). In the case of smaller columns, a lower number of circular cracks were located between the monitored region and the centre of the column and therefore the development of the measured crack started at an earlier loading stage. These observations suggest that, for an equal slab rotation, crack widths are lower in the case of larger columns, where the flexural deformation is distributed between a larger number of cracks.

\section{Development of the failure cracks}

With the internal measurement system, two types of failure cracks could be distinguished. In some cases, the punching failure progressed along a crack that had been first observed as the critical shear crack. However, in other cases, 

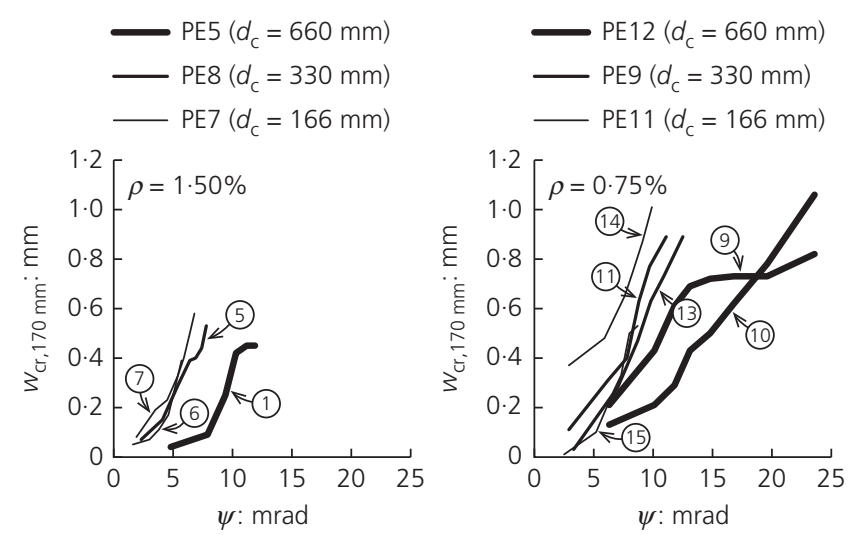

Figure 9. Widths of the flexural cracks as a function of slab rotation (for crack numbers - refer to Figure 8 )

a flatter-angled failure crack developed independently of the critical shear crack (refer to Figures 1(b) and 1(c), respectively).

Progression of the punching failure along the critical shear crack was observed in the specimens with the largest column sizes $\left(d_{\mathrm{c}}=660 \mathrm{~mm}\right)$ : on the north side of the column in specimen PE5 (crack 3 in Figure 8(a)) and on the east side of the column in specimen PE12 (crack 8 in Figure 8(d)). In both cases, the eventual failure cracks were detected having started opening at load levels clearly below the punching capacity: at $76 \%$ of $V_{\mathrm{R}}$ in specimen PE5 and at $85 \%$ of $V_{\mathrm{R}}$ in specimen PE12. Yet, in both of these specimens, the failure cracks in the other monitored sides of the column were of the second type, developing below the critical shear crack. In specimen PE5, at $90 \%$ of the maximum load (the last measurement step), the failure crack on the east side of the column, inclined at $18^{\circ}$ from the horizontal, had a width of approximately $0.3 \mathrm{~mm}$ (crack 2 in Figure 8(a)). However, in specimen PE12, where the failure crack on the east side of the column had a very low inclination, it was not detected even at the last measurement step, although the measurements were taken at $98 \%$ of $V_{\mathrm{R}}$.

In the two specimens with intermediate size columns $\left(d_{\mathrm{c}}=330 \mathrm{~mm}\right.$ : PE8 in Figure 8(b) and PE9 in Figure 8(e)), the failure cracks developed independently of the critical shear cracks in every surveyed region. Both specimens failed during or after performing the internal measurements, while the load had decreased below the maximum applied load $V_{\mathrm{R}}$. On the north side of the column, no strains were measured at the location of the eventual failure crack in either of the slabs. In contrast, on the east side of the column of PE8, a failure crack (with an inclination of $30^{\circ}$ ) was observed to start opening at $86 \%$ of $V_{\mathrm{R}}$ (Figure $8(\mathrm{~b})$ ). The width of the crack, uniform over the whole measured length, increased to $0.7 \mathrm{~mm}$ before the failure. The column penetration, however, which was measured on the west side of the column (Figure 7(a)), started to increase only after the maximum load had been applied. Punching failure of the specimen occurred approximately $20 \mathrm{~min}$ after the loading was stopped, during which period the applied load dropped from the maximum of $985 \mathrm{kN}$ to $835 \mathrm{kN}$ and the column penetration (on the west side of the column) increased from $0.2 \mathrm{~mm}$ to $0.6 \mathrm{~mm}$. In specimen PE9, punching failure occurred while the measurements were being taken. During the last measurement step, a failure crack with an opening of $0.3 \mathrm{~mm}$ (crack 12 in Figure 8(e)) was detected on the east side of the column. Yet, on the west side of the column, increasing column penetration had already been measured at earlier loading stages.

In the specimens supported on the smallest columns $\left(d_{\mathrm{c}}=166 \mathrm{~mm}\right)$, the failure cracks were not detected prior to punching in any of the cases. In specimen PE11, the radial compressive strains at the soffit, which had been decreasing before, started to grow again immediately before the failure. Similar behaviour was also observed in other specimens with even smaller column sizes (Einpaul et al., 2016) and in
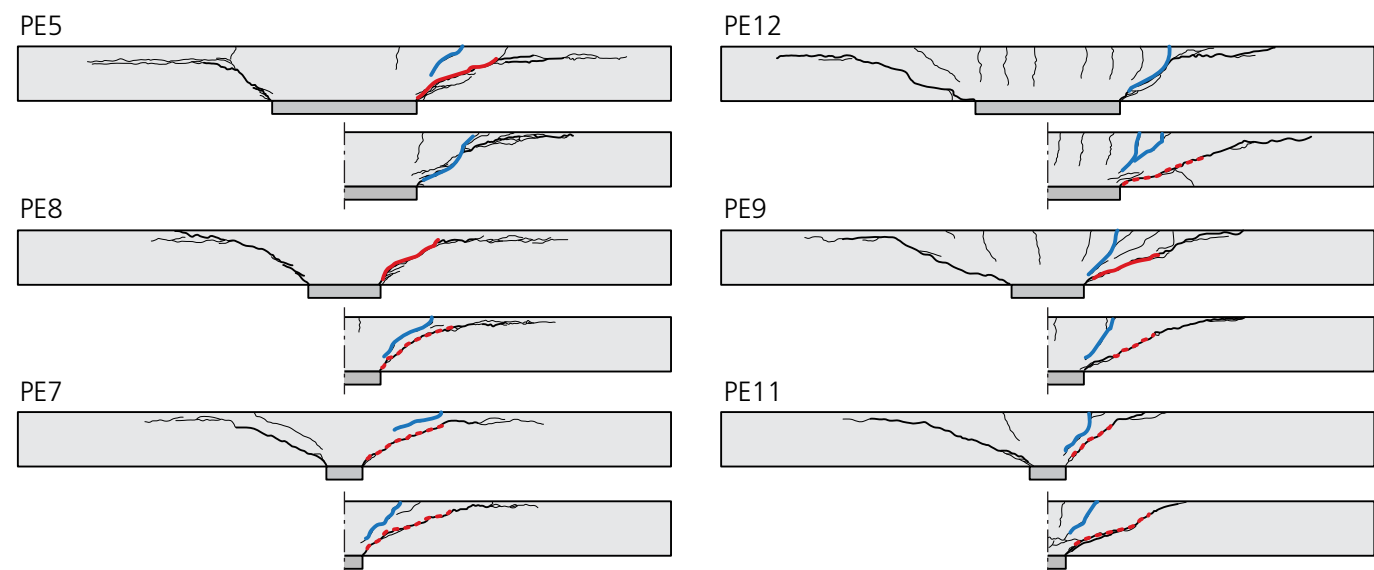

Flexural cracks

Failure cracks, _ detected before the failure

Failure cracks, ..... not detected before the failure

Figure 10. Types of cracks in punching test specimens 
compact footings (Simões et al., 2016a). This suggests that a different failure mode may govern in the case of very high compressive stresses in the punching region.

The different types of cracks for all the specimens are shown in Figure 10. It is interesting to note that the development of failure cracks could be remarkably different not only between specimens but even on different sides of the column in the same slab, although the specimens were nominally axissymmetric (actually, the $\mathrm{N}-\mathrm{S}$ axis had approximately $10 \%$ higher flexural strength and stiffness than the E-W axis due to the orthogonal layout of reinforcing bars that had the same diameter and spacing in both directions (refer to Table 1)). The experiments show that the failure cracks appeared in some slab sectors at lower load levels than in the others, in some cases already at $75-80 \%$ of $V_{\mathrm{R}}$. This can be compared to the observations regarding shear behaviour of beams of Campana et al. (2013), as well as Cavagnis et al. (2015), who have demonstrated that different cracking patterns and consequent differences in mechanical shear transfer actions through the cracks can emerge in different beam specimens of similar geometries and mechanical properties. In slab specimens, however, the initiation of a failure crack did not yet prompt a sudden punching failure but, in several cases, its development could continue in a semi-stable manner.

\section{Interpretation of the failure mechanism}

The critical shear crack theory, a mechanical model developed by Muttoni (2008), is based on an assumption that the punching strength of slabs without shear reinforcement is governed by the width and roughness of the critical shear crack, which develops through the inclined compression strut that carries shear (Muttoni and Fernández Ruiz, 2010a). The physical basis of the model for slender slabs was demonstrated quantitatively by Guidotti (2010), whose model assumed a theoretical failure crack shape and kinematics (rotation and sliding), as shown in Figure 11(a). Analysis of potential mechanisms of stress transfer through that crack suggested that shear in slender slabs is predominantly carried by an inclined conical strut which develops in the lower part of the member. This is explained by lower crack widths in this region, which are associated with larger shear-transfer capacities (Figure 11(b)). Studies on slabs with low slenderness ratios (Simões et al., 2016b) confirmed the main assumptions of the critical shear crack theory also for such elements, with failures again governed by the development of an inclined failure surface that localises the strains. In this case, the failure surface is not necessarily conical and the governing kinematics might be more complex than in slender slabs, but the capacity to transfer shear forces is still governed by the shape, opening and roughness of the failure surface (Simões et al., 2016b).

Two types of punching failures could be distinguished by means of the internal measurements in the specimens

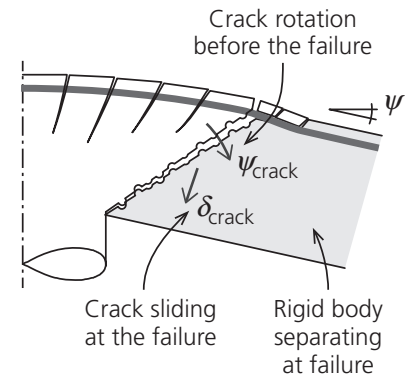

(a)

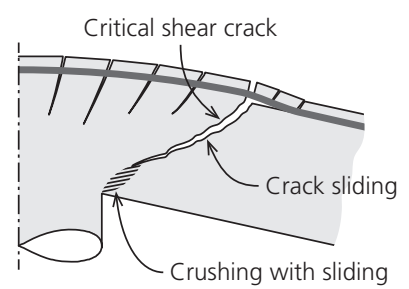

(c)

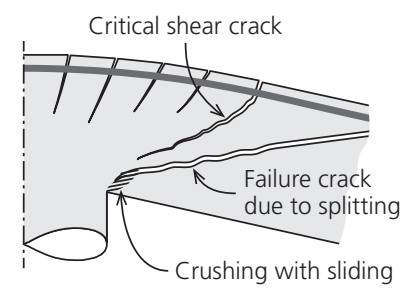

(e)

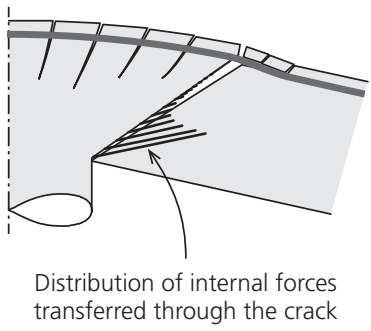

(b)

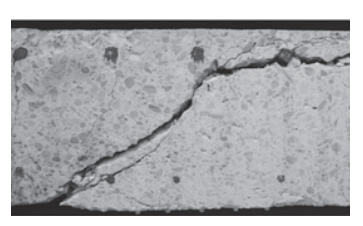

(d)

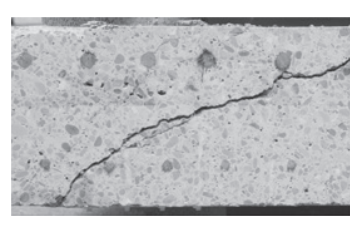

(f)
Figure 11. Interpretation of the test results: (a) kinematics of punching failure assumed in the CSCT; (b) distribution of internal forces transferred through the critical shear crack (adapted from Muttoni and Fernández Ruiz (2010a)); (c) development of a punching failure crack along the critical shear crack; (d) failure crack in specimen PE12 (east); (e) development of a punching failure crack independently of the critical shear crack; (f) failure crack in specimen PE7 (north)

described in the present paper. In some cases, failure occurred along the critical shear crack (Figure 11(c)), which is consistent with the theoretically assumed mechanism shown in Figure 11(a). On the saw-cuts (refer to an example in Figure 11(d)), the lower part of the crack is significantly more damaged, which is consistent with the fact that most of the shear force is carried in this region (Figure 11(b)). In other cases, the failure occurred with a sudden appearance of a flatangled crack that was probably related to splitting (refer to Figures 11(e) and 11(f)), again referring to a failure in the critical region near the column. For both failures, a single crack eventually localised the strains. In addition, the states of strains and stresses in the compression strut close to the edge of the column, which are determined by the geometry and position of the critical shear crack, were governing for the failures. Therefore, the main assumptions of the critical shear crack theory may suitably describe both punching failure types observed in the presented experiments. 


\section{Conclusions}

In this paper, the formation and growth of cracks inside six full-scale punching test specimens was successfully monitored with a newly developed internal measurement system. Both flexural and eventual failure cracks were tracked. The main conclusions made on the basis of the observations are listed below.

- The main results (punching strengths and critical deformations) of the slabs with holes for internal measurements were consistent with the results of previously tested full slabs.

- Based on their mode of development, two types of cracks could be distinguished in the punching regions, namely critical shear cracks and failure cracks due to splitting.

- The critical shear cracks were of flexural origin and developed as predicted by the sector model of Muttoni (2008). The directions of crack opening were approximately perpendicular to the crack lips in the upper part of the cracks, where the kinematics was measured. The widths of the furthermost flexural cracks depended on the total number of cracks within the supported area. Therefore, for equal rotations, the cracks were narrower in specimens with larger column sizes.

- The observed development of splitting failure cracks was different between the specimens and even between different sides of the column in the same specimen.

- Except for some sides of the largest columns, the splitting failures did not occur along pre-existing critical shear cracks but by formation of new (lower-angled) failure cracks.

- The initiation of a splitting crack did not always cause an immediate punching failure of the specimen. Instead, in several cases, the load could still be increased by up to $20 \%$.

\section{Acknowledgement}

The work presented in this paper was funded by the Swiss National Science Foundation (project no. 200021 137658).

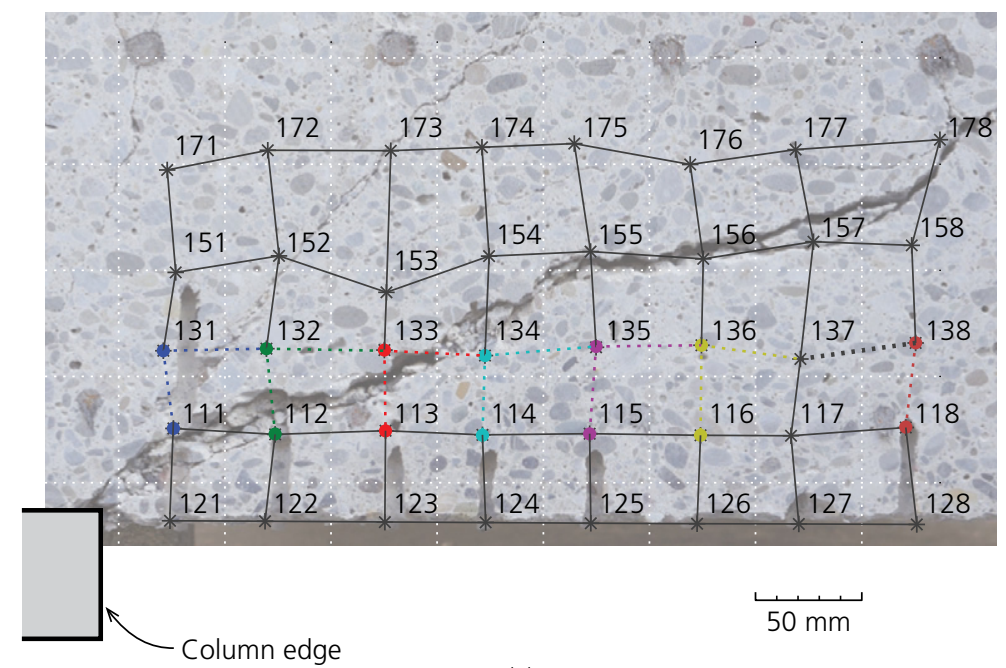

(a)

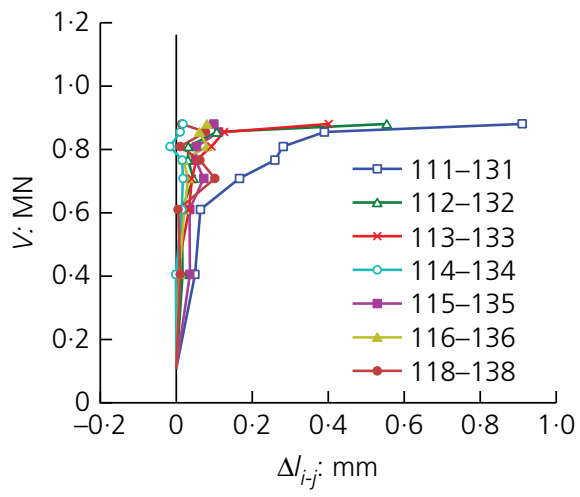

(b)

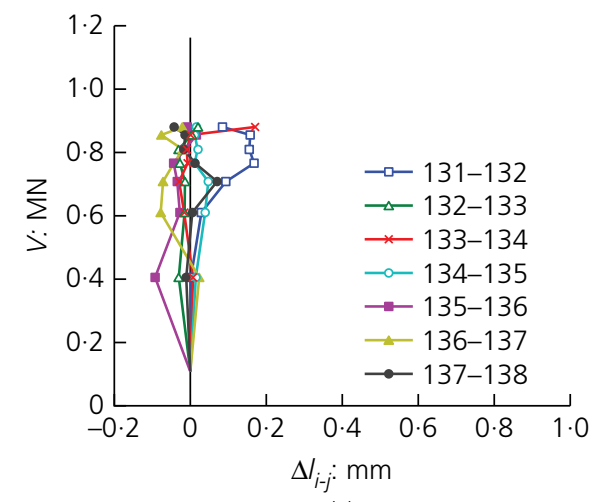

(c)

Figure 12. Example of the measurements obtained, specimen PE9, east side of the column: (a) mesh of the internal points, projection on a vertical plane; (b) example of the development of relative vertical displacements; (c) example of the development of relative horizontal displacements 
The authors would like to express their sincere gratitude for the support received.

\section{Appendix}

This Appendix describes the calculation of approximate crack widths and opening directions from the measured coordinates of the internal measurement points. Measurement of the coordinates of the same internal points at different loading steps allowed the calculation of the relative displacements between the points. In Figure 12(a), the mesh of internal points (projected to a vertical plane) on the east side of the column in specimen PE9 is shown. As an example of the measurements obtained, Figure 12(b) shows the development of the relative displacements (relative to the initial measurements before loading) between the third and fourth (from the top) lines of measurement points as a function of the applied punching load. Opening of a flexural crack, which starts between points $111-131$ at approximately $600 \mathrm{kN}$, is consistently measured at higher levels of load. At the last measurement step, opening of a shear failure crack between points 112-132 and 113-133 can also be recognised. Figure 12(c) shows the horizontal relative displacements on the third line of internal points. The opening of the flexural crack between points 131-132, as well as the opening of a failure crack between points 133-134 at the last measurement step, can also be seen in these curves. Such representation allows assessment of the precision of the measurement system (apparent, e.g. in the curve obtained for displacements between points 118-138 in Figure 12(b) that varies with a range of approximately $0.1 \mathrm{~mm}$ ) and detection of clearly erroneous measurements.

The crack widths and opening directions at different levels of loading were calculated from the coordinates of the measurement points by dividing the mesh of points into triangles. Strains on all sides of each triangle $\left(\varepsilon_{i-j}=\Delta l_{i-j} / l_{i-j}\right)$ (Figure 13(a)) were then converted into principal strains $\left(\varepsilon_{\mathrm{I}, 1-2-3}\right.$ and $\varepsilon_{\mathrm{II}, 1-2-3}$ in Figure 13(b)). The directions and magnitudes of the principal compressive strains in the triangles show the compressive stress field in the slab. However, the mesh

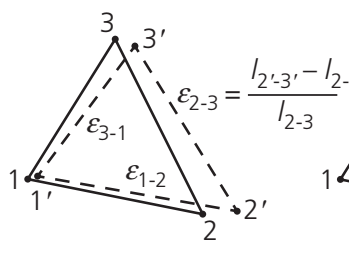

(a)

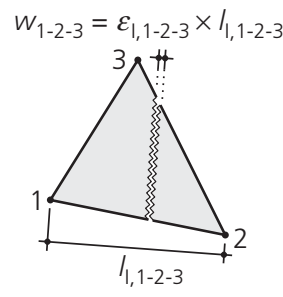

(c)
Figure 13. Conversion of the measured displacements to crack opening $w$ : (a) strains at the edges of the triangles; (b) principal strains; (c) crack opening in the direction of principal tensile strain of internal points was too coarse and the precision of the system too low to obtain reliable information about the compressive strains in concrete. In contrast, the precision was sufficient to follow the formation and kinematics of cracks. Crack widths $w_{\text {cr }}$ and their opening directions at different load steps were calculated by multiplying the maximum principal tensile strains in each triangle by the length of the triangle in the direction of the strain (Figure 13(c)). This represents an assumption that the tensile strain in a triangle was concentrated into a single crack, the direction of which was perpendicular to the direction of principal tension.

\section{REFERENCES}

Campana S, Fernández Ruiz M, Anastasi A and Muttoni A (2013) Analysis of shear-transfer actions on one-way RC members based on measured cracking pattern and failure kinematics. Magazine of Concrete Research 65(6): 386-404, http://dx.doi.org/ 10.1680/macr.12.00142.

Cavagnis F, Fernández Ruiz M and Muttoni A (2015) Shear failures in reinforced concrete members without transverse reinforcement: an analysis of the critical shear crack development on the basis of test results. Engineering Structures 103: 157-173, https://doi.org/ 10.1016/j.engstruct.2015.09.015.

Clément T, Fraccaro M, Muttoni A and Fernández Ruiz M (2012) Essais de Poinçonnement sur Dalles en Béton Armé - Mesures Internes. IBETON, EPFL, Lausanne, Switzerland, Test report (in French).

Einpaul J, Bujnak J, Fernández Ruiz M and Muttoni A (2016) Study on the influence of column size and slab slenderness on punching strength. ACI Structural Journal 113(1): 135-145.

fib (Fédération Internationale du Béton) (2001) fib Bulletin 12: Punching of Structural Concrete Slabs. fib, Lausanne, Switzerland.

Guandalini S, Burdet O and Muttoni A (2009) Punching tests of slabs with low reinforcement ratios. ACI Structural Journal 106(1): 87-95.

Guidotti R (2010) Poinçonnement des Planchers-dalles avec Colonnes Superposées Fortement Sollicitées. PhD thesis, École Polytechnique Fédérale de Lausanne, Lausanne, Switzerland (in French).

Kani GNJ (1964) The riddle of shear failure and its solution. ACI Journal 61(4): 441-467.

Kinnunen S and Nylander H (1960) Punching of Concrete Slabs without Shear Reinforcement. Transactions of the Royal Institute of Technology, No. 158, Royal Institute of Technology, Stockholm, Sweden.

Kupfer H (1973) Das Verhalten des Betons unter mehrachsiger Kurzzeitbelastung unter besonderer Berücksichtigung der zweiachsigen Beanspruchung. Deutscher Ausschuss für Stahlbeton, No. 229, Berlin, Germany (in German).

Muttoni A (2008) Punching shear strength of reinforced concrete slabs without transverse reinforcement. ACI Structural Journal 105(4): $440-450$.

Muttoni A and Fernández Ruiz M (2010a) MC2010: the critical shear crack theory as a mechanical model for punching shear design and its application to code provisions. In $f i b$ Bulletin 57: Shear and Punching Shear in RC and FRC Elements (Thommen-Vidale L (ed)). Fédération Internationale du Béton, Lausanne, Switzerland, pp. 31-60.

Muttoni A and Fernández Ruiz M (2010b) Shear in slabs and beams: may they be treated in the same way? In fib Bulletin 57: Shear and Punching Shear in RC and FRC Elements. Fédération Internationale du Béton, Lausanne, Switzerland, pp. 105-128. 
Sagaseta J, Muttoni A, Fernández Ruiz M and Tassinari L (2011)

Non-axis-symmetrical punching shear around internal columns of RC slabs without transverse reinforcement. Magazine of Concrete Research 63(6): 441-457, http://dx.doi.org/10.1680/ macr.10.00098.

Simões JT, Bujnak J, Fernández Ruiz M and Muttoni A (2016a) Punching shear tests on compact footings with uniform soil pressure. Structural Concrete 17(4): 603-617.
Simões JT, Faria DMV, Fernández Ruiz M and Muttoni A (2016b) Strength of reinforced concrete footings without transverse reinforcement according to limit analysis. Engineering Structures 112: 146-161, https://doi.org/10.1016/j.engstruct.2016. 01.010 .

Vollum RL and Fang L (2014) Shear enhancement in RC beams with multiple point loads. Engineering Structures 80: 389-405, https://doi.org/10.1016/j.engstruct.2014.09.010.

\section{How can you contribute?}

To discuss this paper, please submit up to 500 words to the editor at journals@ice.org.uk. Your contribution will be forwarded to the author(s) for a reply and, if considered appropriate by the editorial board, it will be published as a discussion in a future issue of the journal. 